\title{
Moderate Effects of Managerial Response on Hotel Ratings of Japanese Tourists
}

\author{
일본인 관광객의 숙박 후기 평점에 대한 관리자 응답의 조절효과 \\ Juhyeok JANG(장주혁)*
}

Received: June 15, 2019. Revised: June 24, 2019. Accepted: July 05, 2019.

\section{Abstract}

Purpose - It is a very important issue for the Korean tourism industry to increase tourism revenue by attracting foreign tourists. Although Japanese tourists have been an important part of the Korean tourism industry for a long time, the level of tourist satisfaction including accommodation has been at the worst compared to other foreign visitors, which strongly requires concrete solutions. Therefore, this study focuses on improving the satisfaction level of Japanese visitors in the use of accommodation, and find out the influence of the managerial response.

Research design, data, and methodology - In this study, customer review and managerial response of hotels in Seoul were collected from "Rakuten Travel" which is the most representative online travel agency in Japan. As a result of collecting data from 2016 to 2018, 6,190 customer reviews and 1,241 managerial responses from 120 hotels were used for analysis. In addition, information on the properties of 120 hotels, such as the number of rooms, classification, types of hotel facilities, types of room facilities, accessibility and prices, were collected. To test the hypotheses, moderated multiple regression analysis was conducted with SPSS 22.0.

Results - It was found that only 25 sites, $20.8 \%$ of the total 120 sites, were implementing managerial response and average response rate was $66.42 \%$ among them. As a result of examining the main effects of the hotel attributes on the ratings, accessibility and price are confirmed as effective variables. We also found that the response rate has a significant moderate effect in both the accessibility and price. In other words, there was a significant difference in the influence of accessibility and price on the ratings depending on the response rate. Also, it was confirmed that the response rate is not a pure moderator variable but a quasi moderator variable. Overall, the evidences partially supported the hypothesis.

Conclusion - It was possible to provide important suggestions to the hotel managers who were concerned about managing tourist satisfaction with accessibility problems. It was found that the accessibility problem could be overcome by increasing the response rate. It was also confirmed that high ratings can be more effectively achieved for high priced hotels by increasing the response rate.

Keywords: Managerial Response, Customer Review, Foreign Tourists, Japanese Tourist, Hotel Service, Tourism, Hospitality industry.

JEL Classifications: L83, Z32, Z33.

1. 서론

2018년 한국관광공사가 발표한 한국관광통계에 의하면, 오

*Assistant Professor, Faculty of Media and Communication, Hokkaido University, Japan. Tel : +81-11-706-5379

E-mail : jang.juhyeok@imc.hokudai.ac.jp

(0) Copyright: Korean Distribution Science Association (KODISA)
This 15 an Open Access article distributed under the terms of

This is an Open Access article distributed under the terms of the Creative Commons Attribution Non-Commercial License (https:///creativecommons.org/licenses/by-nc/4.0/) which permits unrestricted properly cited.
늘날 한국의 관광수지는 2001년부터 꾸준히 적자를 기록하고 있으며, 특히 2017년에는 전년도 대비 두 배가량 급격히 증가 된 147 억 달러의 적자를 기록하였다. 이러한 적자는 최근 관 광 지출이 급속히 증가하고 있는 것에 비해, 관광 수입은 2013년부터 6년 가까이 정체되어있는 것에 기인한 현상이라 할 수 있다. 한국의 경제 성장은 수출 주도의 경제로 인한 것 이지만, 관광 부문은 최근의 경제 성장을 위한 또 다른 요인이 될 수 있다(Lee, 2012). 따라서 외국인 관광객의 유치 및 재방 문을 유도하여 관광 수입을 증가시키는 것은, 우리의 관광산업 에 있어서 대단히 중요한 과제이며, 구체적인 대응방안 역시 
중요하게 다루어져야 할 논점이라 할 수 있다.

한편, 2017년 한국관광공사의 외래관광객실태조사 보고서에 의하면, 방한 일본인 관광객은 약 230 만 명으로 중국에 이어 두 번째로 많은 것으로 기록되었으며, 그 외에도 재방문 횟수 가 9.4 회(외국인 전체 평균 4.1 회), 재방문 비율도 $70.5 \%$ (외국 인 전체 평균 $53.3 \%$ )로서, 전체 평균을 크게 상회하는 등, 한 국 관광산업에 있어서 중요하게 다루어져야 할 대상임이 확인 되었다. 그러나 동시에 진행된 관광만족도 조사에서는 숙박부 문을 포함하여 전반적으로 최하수준인 것으로 나타나, 만족도 향상에 대비한 해결책을 시급히 강구해야 하는 상황이다. 만족 도는 재방문 의도 및 구전활동과 같은 소비 관련 행동에 영향 을 미치는 중요한 개념이기 때문이다(Park \& Chung, 2016).

이에 대한 시사점을 제공하고자, 본 연구에서는 방한 일본 인 관광객의 숙박 만족도 향상에 초점을 맞추어, 최근 주목받 는 Managerial Response(이하: MR)활동이 숙박 만족도 향상 에 미치는 영향에 대해서 확인하고자 한다. 먼저 일본인 관광 객의 숙박후기에 대한 $\mathrm{MR}$ 의 현황을 확인함과 동시에, 호텔관 리자가 $\mathrm{MR}$ 을 실시함으로써, 해당 숙박시설의 평점 개선에 어 떠한 효과를 기대할 수 있는지를 확인한다. 구체적으로는 호텔 시설의 각종 고유 속성이 평점에 미치는 영향을 $\mathrm{MR}$ 이 어떻게 조절하는지를 살펴봄으로써, 선행연구에서는 중요하게 고려되 지 않았던 MR의 조절효과에 대해 명확히 규명하고자 한다.

\section{2. 이론적 배경 및 가설 설정}

\section{1. 사후 품질 관리 수단으로서의 $\mathrm{MR}$}

최근의 여행상품의 거래가 이루어지는 온라인 예약사이트들 은, 숙박 후기 작성 기능과 더불어 이러한 후기에 대해 호텔 관리자가 MR을 실시할 수 있도록 하는 기능도 동시에 제공 하고 있는데, 이러한 $\mathrm{MR}$ 은 서비스 만족도 향상을 위한 중요 한 CRM의 수단이 될 수 있기 때문이다(Xie, Zhang, Zhang, Singh, \& Lee, 2016). 서비스는 고객이 존재하는 서비스 접점 (Service Escape)에서 생산됨과 동시에 소비되는 특성을 가지 고 있어, 제품과는 달리 품질의 사전 점검이라는 개념이 성립 되지 않는다(Jang, 2016). 게다가 프론트와 객실 업무 등 인적 요소에 의한 서비스는 품질이 균일하지 못하며, 상황에 따라 변동하게 되는 이질적인 특성을 가지고 있다(Parasuraman, Zeithaml, \& Berry, 1985). 이러한 요인으로 인하여 숙박업계의 서비스는 높은 서비스 실패의 가능성을 가지고 있는데, 이렇게 필연적으로 발생하는 서비스 실패에 대해서는 사전 품질관리 를 철저히 하는 것 이상으로 사후 품질 관리를 철저히 하는 것이 중요한 과제라 할 수 있으며(Jang, 2016), 이때 고객 후 기에 대한 MR이 바로 사후 품질 관리의 일환으로서 활용될 수 있는 것이다. 적절한 사후 관리를 통해서, 경우에 따라서는 애초에 서비스 실패를 경험하지 않았던 고객보다도 더 높은 만족도를 이끌어낼 수도 있기 때문에(Black \& Kelley, 2009; Xie et al., 2016), MR은 매우 중요한 역할을 수행한다고 할 수 있다.

\section{2. 평판 관리 수단으로서의 $M R$}

서비스 실패에 대한 사후 관리가 필요시 되었을 때, 예전에
는 서비스 실패를 경험한 해당고객과의 개별적인 연락을 통해 실시하는 것이 일반적이었다(Xie et al., 2016). 하지만 이러한 사후 관리 방법의 파급효과는 굉장히 제한적이어서, 해당고객 의 만족도 향상과 개별적 구전활동에 의한 신규고객 확보의 수준에 지나지 않았다. 이 때 만약 구전활동이 이루어지지 않 는다면, 신규고객확보는 물론 기대할 수 없다는 한계점도 존재 하였다.

하지만, 온라인 예약사이트에서 이러한 사후 관리를 $\mathrm{MR}$ 을 통해 실시하면, 장기간 온라인상에 기록으로서 남게 되어, 해 당 호텔에서의 숙박을 검토하는 다수의 잠재고객에게 평점 등 숙박 후기 정보와 함께 제공되게 된다. 이러한 평점 등의 숙박 후기 정보는 잠재 고객의 의사결정 활동에 있어서도 중요한 정보원으로 활용되기 때문에(McCarthy, Stock, \& Verma, 2010), 그러한 정보와 함께 MR을 부수적으로 제공함으로써 호텔의 이미지 향상을 기대할 수 있다(Xie et al., 2016). 최근 인터넷 웹 사이트 및 온라인 소셜 커뮤니티의 인기가 급증함 에 따라, 이러한 온라인 수단을 통해 호텔 이미지를 강화하는 등의 평판개선은 필수적인 전략이 되었다(Lee \& Kwag, 2016). 이러한 평판 관리를 통해, 기존 고객의 만족도 향상뿐 아니라, 신규고객 확보에도 도움이 될 수 있다.

\section{3. $\mathrm{MR}$ 관련 선행연구 고찰}

$\mathrm{MR}$ 에 관한 연구는 주로 정량적인 방법을 중심으로 실행되 어왔으며, 그 중에서도 특히 데이터베이스를 활용하는 접근법 과, 실험에 의한 접근법이 주로 사용되어 왔다. 데이터베이스 를 활용하는 접근법은 온라인 호텔 리뷰에 축적된 대량의 후 기 및 $\mathrm{MR}$ 데이터를 수집하여, $\mathrm{MR}$ 의 속성이 향후 평점과 레 뷰 수 등의 고객 참여 활동에 미치는 영향을 확인하는데 주된 초점을 맞추고 있다. 예를 들어, $\mathrm{Gu}$ and $\mathrm{Ye}(2014)$ 는 부정적인 후기를 남긴 고객은, $\mathrm{MR}$ 을 받는 것으로 인해 만족도가 개선 되며, $\mathrm{MR}$ 을 받지 못한채 다른 후기의 $\mathrm{MR}$ 을 관찰하게 되면 만족도가 저하된다는 것을 확인하였다. 또한 Xie, Zhang, and Zhang(2014)은 입지관련 후기에 대한 MR은 호텔의 재무성과 에 긍정적인 효과를 가져오며, 객실의 청결도와 관련된 후기에 대한 MR은 호텔의 재무성과에 대해 악영항을 끼치기 때문에 MR전략이 선택적이어야 함을 확인하였다. Xie et al.(2016)은 $\mathrm{MR}$ 의 비율이 증가하는 것으로 인해 평점과 고객 후기 건수가 증가하는 것을 확인하였으며, 평점과 후기 건수가 재무성과에 미치는 영향을 유의하게 조절하는 것도 확인하였다. Proserpio and Zervas(2017)는 MR을 실시하는 호텔은 평점이 0.12 증가 하고, 고객 후기 수가 $12 \%$ 증가하며, 부정적인 후기의 건수는 줄어들지만 길이는 다소 길어지는 것을 확인하였다. Xie, Kwok, and Wang(2017)은 고급호텔과 중저가호텔을 나누어서 재무성과를 확인하고 있으며, 고급호텔의 경우에는 $\mathrm{MR}$ 이 프 론트 직원에 의한 것일수록, 장문일수록, 빠른 시일 내에 이루 어질수록 재무성과에 긍정적인 영향을 끼치며, 중저가호텔은 $\mathrm{MR}$ 이 고위직급의 관리자에 의한 것일수록, 간결한 단문일수 록 재무성과에 긍정적인 영향을 가져오는 것을 확인하였다. $\mathrm{Li}$, Cui, and Peng (2017)은 빠른 MR속도, 많은 MR건수에 의해, 더 많은 고객 후기가 작성되며 평점도 높아지고, 인기도순위도 상승하는 것으로 확인되었다.

이처럼, 선행연구에서는 $\mathrm{MR}$ 의 갖가지 속성에 대해서, 그 영 향력을 다각도로 확인하고 있다. 선행연구에서 주로 사용되는 MR의 속성으로서는 MR비율(e.g.: Rose \& Blodgett, 2016; Xie 
et al., 2016), MR건수(e.g.:Li et al., 2017; Xie et al., 2017), MR문자수(e.g.: Li et al., 2017; Xie et al., 2017), MR속도 (e.g.: Min, Lim, \& Magnini, 2015)가 있으며, 이에 대한 결과 로서는 주로 평점(e.g.:Chevalier, Dover, \& Mayzlinn, 2018; Li et al., 2017)과 후기 건수(e.g.:Chevalier, Dover, \& Mayzlinn, 2018; Li et al., 2017), 그리고 RevPAR 등의 재무성과(e.g.: Lui, Bartosiak, Piccoli, \& Sadhya, 2018; Xie et al., 2016)가 사용되고 있다. 단, RevPAR 등의 호텔 재무 데이터를 단일 호텔 단위로 파악하는 것은 어렵기 때문에, 재무성과와의 연관 성을 고찰한 연구는 그 수가 극히 제한적인 상황이다.

또한 실험에 의한 접근법은 연구대상자를 몇 개의 소그룹으 로 분류하여, 각각 조건을 달리한 $\mathrm{MR}$ 을 관찰시킨 후 그 반응 을 측정·비교하는 방식을 취한다. 이 접근법을 택한 선행연구 들은 데이터베이스를 활용한 접근법과 비교했을 때, 보다 정성 적인 속성에 초점을 맞추고 있음을 알 수 있다. 예를 들어, Min et al.(2015)은 부정적인 고객 후기에 대한 MR이 의역 표 현(Paraphrasing Statement)과 공감 표현(Empathy Statement) 을 포함했을 때, 만족도 향상을 기대할 수 있는 것을 확인하였 고, Wei, Miao, and Huang(2013)은 어느 후기에 대해서도 적 용 가능한 추상적인 MR과 특정 후기에 대해서만 적용 가능한 개별적인 $\mathrm{MR}$ 간의 고객 평가를 비교하여, 부정적인 후기에 대 해서는 개별적 $\mathrm{MR}$ 이 만족도 향상에 기여한다는 것을 확인하 였다.

이처럼 선행 연구들은 $\mathrm{MR}$ 의 특정 속성이 어떠한 효과를 갖 는지에 대해 초점을 맞추어 진행되어 왔다. 즉, 대부분 $\mathrm{MR}$ 의 속성을 독립변수로 간주하여 왔으며, 따라서 $\mathrm{MR}$ 의 조절효과 에 대한 고찰은 부족한 실정이다. $\mathrm{MR}$ 의 조절효과를 고찰한 소수의 선행연구(e.g.: Gu \& Ye, 2014; Xie et al., 2016)들도 존재하지만, 재무성과에 대한 조절효과를 검증하는데 그치는 등, 극히 제한된 범위 내에서만 의논이 진행되어 왔다. 게다가 국내에 있어서는 MR에 대한 연구가 전무하여, MR의 현황에 대한 실태 파악조차 되어 있지 않는 등 많은 과제가 남아있는 상황이다.

따라서 본 연구에서는 국내의 MR에 대한 현황을 명확히 파 악한 후, 이와 함께 호텔의 입지·시설·가격·등급 등의 각종 고 유 속성이 평점에 미치는 영향을 $\mathrm{MR}$ 이 어떻게 조절할 수 있 는지를 중점적으로 검증하고자 한다.

\section{4. 가설 설정}

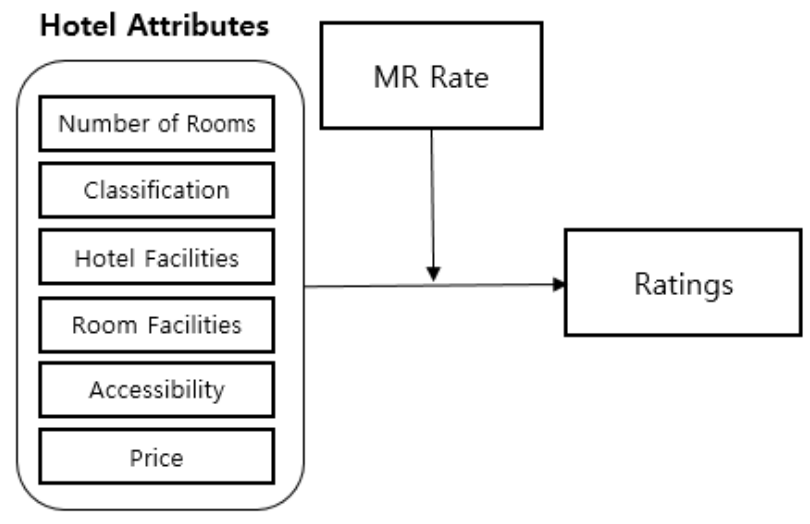

아직까지 한 가지로 합의된 이론이 정착된 것은 아니지만, 서비스 품질은 고객의 기대품질과 실제로 경험된 품질을 비교 하는 측정방법이 일반적이라는 의견이 모아지고 있다 (Shaw-Ching Liu, Sudharshan, \& Hamer, 2000). 예를 들어, Grönroos(1990)은 기대와 경험의 차이로 인해 서비스의 품질 이 결정된다고 주장하면서, 기대와 경험을 형성하는 하위요소 를 열거한 구체적인 모델을 제시하고 있으며, Parasuraman et al.(1985)는 실제로 경험된 품질을 파악하는 것만으로는 서비 스의 품질을 적절히 평가할 수 없다고 지적하면서, 고객의 기 대의 중요성을 강조하고 있다. 이와 같이, 기대라는 개념은 오 랫동안 서비스 품질 평가에 있어서 중요한 개념으로 다루어져 왔다.

숙박 후기에 대해서 호텔 관리자가 적극적으로 $\mathrm{MR}$ 을 실시 하면, 잠재 고객이 해당 호텔에 대한 정보 수집을 위해 숙박 후기를 열람했을 때, 그들에게 추가적인 정보를 제공할 수 있 게 된다. 즉, 잠재 고객은 숙박 후기의 일방적인 의견에 영향 을 받는 것이 아니라, 호텔 측의 의견도 동시에 고려하게 됨으 로써, 보다 균형 있고 객관적인 정보를 취득할 수 있다. 이는 고객의 정보를 현실적인 수준으로 조정하는 효과를 가지게 되 며, 과도한 기대를 가지게 하는 현상을 억제할 수 있다. 결과 적으로 숙박서비스에 대한 기대품질수준과 경험된 품질이 가 깝게 일치하게 되어, 고객의 만족도가 상승하고 평점의 증가를 가져올 것으로 예상할 수 있다.

\section{$\mathrm{H}$ : $\mathrm{MR}$ 은 호텔 속성이 평점에 미치는 영향을 긍정적으로 조절한다}

\section{3. 연구방법론}

본 연구에서는 일본의 대표적 호텔 예약 사이트인 라쿠텐 트래블 일본어사이트에 등록된 서울 소재 호텔의 숙박 후기 및 MR 데이터를 활용하도록 한다. 라쿠텐 트래블은 Jaran.net 과 함께 일본을 대표하는 로컬 호텔 예약 사이트이며, 일본인 이 주요 타깃 고객이다. 여기서 라쿠텐 트래블은 Jaran.net에 비해 한국 호텔에 대한 더 많은 수의 후기가 공유되고 있으며, TripAdvisor등의 글로벌 플랫폼과 비교하여 온전히 일본관광객 을 대상으로 한 현황과 효과를 파악할 수 있기 때문에, 라쿠텐 트래블을 조사 대상 플랫폼으로 선정하였다.

또한 외래 관광객 실태 조사 보고서에 의해 일본인 관광객 의 $80 \%$ 가량이 서울을 방문하는 것으로 확인되었기 때문에, 데 이터 수집에 있어서는 조사의 효율성을 고려하여 서울 소재 호텔을 대상으로 하였다. 2016년부터 2018년까지의 3년간의 데이터를 수집한 결과, 총 147 개의 호텔로부터 6,251 건의 고 객후기 데이터를 수집할 수 있었다. 이 중에서 3년간 누적 레 뷰건수가 5건 미만인 27 개의 호텔을 분석에서 제외하였으며, 최종적으로 120 개 호텔의 6,190 건의 고객 후기 데이터와 1,241 건의 MR데이터가 활용되었다. 또한 추가적으로 120 개의 호텔에 대한 속성, 즉 라쿠텐 트래블에서 제공하는 객실수(호 텔 규모), 등급, 관내시설 종류, 객실시설비품 종류, 접근성(역 에서부터 도보 거리), 가격 등의 정보를 동시에 수집하였다. 데이터 수집에는 웹 크롤링 프로그램 WebHarvy를 사용하였으 며, 분석에는 SPSS 22.0을 사용하였다.

Figure 1: Research Model 


\section{4. 연구결과}

\section{1. 분석대상 표본의 특성과 국내 $\mathrm{MR}$ 의 현황}

기술통계분석을 실시하여, 연구대상인 120 개 시설의 호텔의 특성을 파악하였다. <Table 1>을 통해 연구 대상 호텔들의 MR 실시 여부를 살펴보면, 전체 120 개 호텔 중 25개 호텔만 이 MR을 실시하고 있어 $20.8 \%$ 의 수치를 기록하였다. 이는 해 외 호텔을 대상으로 한 선행 연구에서 조사된 수치(Table 2)로 부터 크게 벗어나지 않은 비슷한 수준임을 알 수 있다. 다만, 선행연구에서는 국제적으로 범용되는 TripAdvisor 등의 플랫폼 을 대상으로 조사를 했기 때문에, 본 조사가 일본인들이 주로 사용하는 로컬 플랫폼을 대상으로 했다는 점을 고려하면, 비교 적 높은 수준의 $\mathrm{MR}$ 실시율이 관찰되었다고 할 수 있다. 또한 호텔 등급을 살펴보면, 1 성급 호텔은 11개 시설(9.2\%), 2성급 호텔은 11 개 시설(9.2\%), 3성급 호텔은 26 개 시설( $21.7 \%), 4$ 성급 호텔은 61 개 시설(21.7\%), 5성급 호텔은 11 개 시설 $(9.2 \%)$ 로, 3성급과 4성급 호텔의 비중이 높은 편이었다. 호텔 의 규모적 특성을 나타내는 객실수에 대해서는 100 개 이하가 36 개 시설(30.0\%), 101 개 이상 200 개 이하가 32 개 시설 $(26.7 \%), 201$ 개 이상 300 개 이하가 18 개 시설(30.0\%), 301 개 이상 400 개 이하가 18 개 시설( $15.0 \%), 401$ 개 이상이 13 개 시 설(10.8\%)로, 전체적으로 중소규모 호텔을 중심으로 비교적 고 른 분포로 표본이 수집되었다.

Table 1: Descriptive Statistics

\begin{tabular}{|c|c|c|c|}
\hline \multicolumn{2}{|c|}{ Demographic Properties } & Frequency & Percent(\%) \\
\hline \multirow{2}{*}{$\begin{array}{c}\text { MR } \\
\text { Implementation }\end{array}$} & YES & 25 & 20.8 \\
\hline & NO & 95 & 79.2 \\
\hline \multirow{5}{*}{$\begin{array}{c}\text { Hotel } \\
\text { Classification }\end{array}$} & 1-star & 11 & 9.2 \\
\hline & 2-star & 11 & 9.2 \\
\hline & 3-star & 26 & 21.7 \\
\hline & 4-star & 61 & 50.8 \\
\hline & 5-star & 11 & 9.2 \\
\hline \multirow{5}{*}{$\begin{array}{l}\text { Number of } \\
\text { Rooms }\end{array}$} & $\sim 100$ & 36 & 30.0 \\
\hline & 101 200 & 32 & 26.7 \\
\hline & $201 \sim 300$ & 21 & 17.5 \\
\hline & $301 \sim 400$ & 18 & 15.0 \\
\hline & $401 \sim$ & 13 & 10.8 \\
\hline \multicolumn{2}{|c|}{ Total } & 120 & 100 \\
\hline
\end{tabular}

Table 2: MR rate in Precedent Research

\begin{tabular}{|c|c|c|}
\hline Research & MR rate & Period \\
\hline Park and Allen(2013) & TripAdvisor 18.0\% & 2010.10-2011.9 \\
\hline Gu and Ye(2014) & Ctrip.com 23.4\% & $\sim 2009.10$ \\
\hline Xie et al.(2016) & TripAdvisor 19.2\% & 2005.1 2011.6 \\
\hline Proserpio and & TripAdvisor 31.5\% & $2001(\mathrm{~T})$ \\
Zervas(2017) & Expedia 2.3\% & 2004 2013(E) \\
\hline Li et al.(2017) & TripAdvisor 32.7\% & 2004 2014 \\
\hline
\end{tabular}

출처 : 필자 작성
Table 3: Specification of MR

\begin{tabular}{|c|c|c|c|}
\hline \multicolumn{2}{|c|}{ Variable } & Frequency & Percent(\%) \\
\hline \multirow{4}{*}{$\begin{array}{l}\text { MR Rate } \\
(M=66.42 \\
S D=36.55)\end{array}$} & $\sim 25 \%$ & 5 & 20.0 \\
\hline & $26 \% \sim 50 \%$ & 4 & 16.0 \\
\hline & $51 \% \sim 75 \%$ & 3 & 12.0 \\
\hline & $76 \% \sim$ & 13 & 52.0 \\
\hline \multirow{5}{*}{$\begin{array}{c}\text { MR Speed } \\
(M=41.21 \\
S D=57.13)\end{array}$} & 〜10days & 9 & 36.0 \\
\hline & 11 20days & 6 & 24.0 \\
\hline & 21 30days & 0 & 0.0 \\
\hline & 31 40days & 3 & 12.0 \\
\hline & 41days & 7 & 28.0 \\
\hline \multirow{3}{*}{$\begin{array}{c}\text { MR Length } \\
(\mathrm{M}=121.96 \\
\mathrm{SD}=76.53)\end{array}$} & $\sim 100$ char & 10 & 40.0 \\
\hline & 101 200char & 9 & 36.0 \\
\hline & 201 300char & 6 & 24.0 \\
\hline \multicolumn{2}{|c|}{ Total } & 25 & 100 \\
\hline
\end{tabular}

다음으로, <Table 3>과 같이, MR을 실시 중인 25개의 호텔 을 대상으로 $\mathrm{MR}$ 의 현황을 살펴보았다. 먼저 숙박후기 건수 대비 MR 건수의 비율을 나타내는 $\mathrm{MR}$ 비율의 지표를 살펴보 면, 평균은 약 $66 \%$ 로 나타났으며, 전체 25 개 시설 중 절반 이 상에 해당하는 13 개 시설의 응답률이 $76 \%$ 를 상회하는 등, 높 은 $\mathrm{MR}$ 비율이 관찰되었다. 다음으로, 숙박후기가 작성된 후 $\mathrm{MR}$ 이 작성될 때까지 소요된 일수를 나타내는 $\mathrm{MR}$ 속도의 지표 를 살펴보면, 25 개 시설 중 15 개의 시설이 20 일 이내에 MR을 작성하는 것으로 나타났다. 평균은 약 41일로 다소 많은 시간 이 걸리는 것으로 나타났으나, 이는 응답까지 평균 211일, 180 일, 132 일이 소요된 3 개 시설의 영향에 의한 것으로, 이 3 시설을 제외한 평균은 22.98 일이었다. 또한 $\mathrm{MR}$ 길이의 평균은 121.96자로, 주로 200자 이하의 단문으로 작성되는 것으로 나 타났으며, 이는 <Table 4>에서 볼 수 있듯이, 숙박 후기의 길 이 $(\mathrm{M}=176.91, \quad \mathrm{SD}=53.10)$ 보다 유의하게 짧은 것 $(\mathrm{t}=3.024$, $\mathrm{p}=0.006)$ 으로 나타났다. 요건만을 전달하는 숙박 후기와 달리, 본문의 앞뒤에 인사말이 포함되는 등 격식을 갖추어 작성되는 $\mathrm{MR}$ 이 오히려 짧은 것으로 나타난 것은, 일본어로 $\mathrm{MR}$ 을 작성 함에 따른 언어적인 한계에 의한 것으로 판단된다.

Table 4: Paired t-test between Review and MR

\begin{tabular}{|c|c|c|c|c|}
\hline Variable & M & SD & t & sig. \\
\cline { 1 - 3 } Review Length & 176.91 & 53.10 & \multirow{2}{*}{3.024} & \multirow{2}{*}{0.006} \\
\cline { 1 - 3 } MR Length & 121.96 & 76.53 & & \\
\hline
\end{tabular}

\section{2. $\mathrm{MR}$ 의 조절효과}

본 연구는 호텔 속성이 평점에 미치는 영향을 MR비율이 긍 정적으로 조절하는지를 살펴보기 위해, 조절회귀분석을 실시하 였다. 이에 따른 결과는 <Table 5>에 제시되어 있다. 상호작용 변수를 사용함에 있어서 다중공선성의 문제가 항상 부수적으 로 발생하게 되는데, 이를 해결하기 위해 변수를 그대로 사용 치 않고, 각각 평균중심화한 값을 분석에 사용하였으며, 그 결 과 VIF가 모든 변수에 대해 10 을 넘지 않는 것으로 다중공선 성 문제가 해결되었음을 확인하였다. 
Table 5: Correlation Coefficients between independent variables

\begin{tabular}{|c|c|c|c|c|c|c|c|c|}
\hline variables & Mean & Standard Deviation & 1 & 2 & 3 & 4 & 5 & 6 \\
\hline 1. Number of Rooms & 203.95 & 152.340 & 1 & & & & & \\
\hline 2. Hotel Classification & 3.42 & 1.081 & $0.732^{\star *}$ & 1 & & & & \\
\hline 3. Hotel Facilities & 12.70 & 7.354 & $0.522^{* *}$ & $0.634^{* *}$ & 1 & & & \\
\hline 4. Room Facilities & 23.74 & 6.795 & $0.321^{* *}$ & $0.431^{* *}$ & $0.609^{* *}$ & 1 & & \\
\hline 5. Accessibility & 3.71 & 2.977 & 0.042 & 0.069 & $0.205^{*}$ & 0.128 & 1 & \\
\hline 6. Price & $8,772.27$ & $5,114.74$ & $0.539^{* \star}$ & $0.655^{\star \star}$ & $0.625^{\star *}$ & $0.424^{* *}$ & 0.120 & 1 \\
\hline
\end{tabular}

먼저 <Table 5>의 Model1을 통해 호텔속성이 평점에 미치 는 주효과를 살펴본 결과, 접근성(=역으로부터의 도보시간)과 가격이 유효한 변수임을 확인하였다. 즉, 역으로부터의 도보시 간이 길어질수록 평점은 하락하며 $(\mathrm{B}=-0.031, \mathrm{Beta}=-0.233)$, 가 격이 올라갈수록 평점이 증가함이 $(\mathrm{B}=2.202 \mathrm{E}-5, \quad \mathrm{Beta}=0.291)$ 확인되었다. 구체적으로는 역으로부터의 도보시간이 1 분 길어 질수록, 평점은 0.031 가량 하락하며, 가격이 1000 엔 증가할수 록 평점은 0.023 가량 증가한다. 높은 가격이 높은 평점을 유도 하는 이유로는 <Table $5>$ 에서와 같이 가격이 증가함에 따라 호텔의 규모가 커지고( $\mathrm{r}=0.539)$, 등급이 높아지며 $(\mathrm{r}=0.655)$, 관 내시설종류가 많아지고 $(\mathrm{r}=0.625)$, 객실시설비품종류도 많아지 는 $(r=0.424)$ 현상에 기인한 것이라 예상된다. 또한 접근성 (Beta=-0.233)과 가격(Beta=0.291)의 Beta값으로부터 가격이 접근성보다 평점에 더 큰 영향을 미치는 것으로 분석되었다.

다음으로 <Table 6>의 Model3을 통해 MR비율의 조절효과 를 검증한 결과, 접근성과 가격에 있어서 유의함이 확인되었 다. 즉, $\mathrm{MR}$ 비율의 고저에 따라서 접근성과 가격이 평점에 미 치는 영향은 유의한 차이가 발생하는 것이 확인되었다. 보다 구체적으로는, 상호작용항인 접근성 $\times \mathrm{MR}$ 비율의 계수가 양의 값 $(\mathrm{B}=0.102, \mathrm{Beta}=0.207)$ 을 가지기 때문에, $\mathrm{MR}$ 비율이 높아질 수록 접근성이 평점에 미치는 음의 효과를 완화시키는 것을 알 수 있다. 또한, 상호작용항 가격 $\times \mathrm{MR}$ 비율의 계수도 역시 양 의 값( $\mathrm{B}=0.000, \mathrm{Beta}=0.368)$ 을 가지고 있으며, 이에 따라 MR비 율이 높아질수록 가격이 평점에 미치는 양의 효과를 더욱 증폭 시키는 것이 확인 되었다 이는 MR비율의 고저수준에 따른 접 근성과 평점의 관계, 그리고 가격과 평점의 관계를 나타낸 <Figure 2>를 통해서도 확인할 수 있다. <Figure 2>의 접근성 의 그래프를 보면, 역으로부터의 도보 거리가 멀어질수록 MR비 율이 낮은 호텔은 평점이 하락하는 경향을 보이고 있으나, MR 비율이 높은 호텔은 이 음의 효과를 완화하며, 결과적으로는 오 히려 평점 상승을 이끌어내고 있다. 또한 <Figure 2>의 가격 그 래프를 보면, 전체적으로 가격이 상승할수록 평점이 증가하는 경향이 있으나, MR비율이 높은 호텔은 MR비율이 낮은 호텔과 비교하여 평점의 상승폭이 유의하게 큰 것을 알 수 있다.

마지막으로 <Table 6>의 Model2에서 조절변수인 MR비율이 평점에 유의한 영향을 끼치는 것을 볼 수 있는데, 이로 인해 본 연구에서 관찰된 조절효과는 순수조절효과가 아닌, 유사조 절효과였음을 알 수 있다. 즉, MR비율은 독립변수로서도 직접 적으로 종속변수인 평점에 유의한 영향을 끼치며, MR비율이 높아질수록 평점도 높아짐을 알 수 있다. 이것은 $\mathrm{MR}$ 비율을 독립변수로 두고 평점의 증감을 관찰한 Xie et al.(2016)와 일 치하는 결과이며, 이에 따라 $\mathrm{MR}$ 비율이 평점에 미치는 영향은 플랫폼의 종류와 관찰대상의 국적을 막론하고 보다 일반화 가 능한 포괄적 현상임을 추측할 수 있다.
Table 6: Regression Analysis

\begin{tabular}{|c|c|c|c|}
\hline Variable & Model1 & Model2 & Model3 \\
\hline Number of Rooms & $\begin{array}{l}0.000 \\
(0.000)\end{array}$ & $\begin{array}{c}0.000 \\
(0.000)\end{array}$ & $\begin{array}{c}0.000 \\
(0.000)\end{array}$ \\
\hline Hotel Classification & $\begin{array}{c}0.024 \\
(0.054)\end{array}$ & $\begin{array}{c}0.044 \\
(0.052)\end{array}$ & $\begin{array}{l}-0.002 \\
(0.055)\end{array}$ \\
\hline Hotel Facilities & $\begin{array}{l}-0.004 \\
(0.007)\end{array}$ & $\begin{array}{l}-0.002 \\
(0.007)\end{array}$ & $\begin{array}{c}0.004 \\
(0.007)\end{array}$ \\
\hline Room Facilities & $\begin{array}{c}0.011 \\
(0.006)\end{array}$ & $\begin{array}{c}0.009 \\
(0.006)\end{array}$ & $\begin{array}{l}0.012^{*} \\
(0.006)\end{array}$ \\
\hline Accessibility & $\begin{array}{c}-0.031^{* *} * 1 \\
(0.012)\end{array}$ & $\begin{array}{l}-0.029^{*} \\
(0.011)\end{array}$ & $\begin{array}{l}-0.025^{*} \\
(0.011)\end{array}$ \\
\hline Price & $\begin{array}{c}2.254 \mathrm{E}-5^{*}{ }^{* 2} \\
(0.000)\end{array}$ & $\begin{array}{c}2.202 \mathrm{E}-5^{*} \\
(0.000)\end{array}$ & $\begin{array}{c}3.183 E-5^{* *} \\
(0.000)\end{array}$ \\
\hline MR Rate & & $\begin{array}{l}0.342^{* \star} \\
(0.105)\end{array}$ & $\begin{array}{l}0.394^{* *} \\
(0.119)\end{array}$ \\
\hline $\begin{array}{c}\text { Number of Rooms } \\
\times \text { MR Rate }\end{array}$ & & & $\begin{array}{l}-0.001 \\
(0.001)\end{array}$ \\
\hline $\begin{array}{c}\text { Hotel Classification } \\
\times \text { MR Rate }\end{array}$ & & & $\begin{array}{l}-0.509^{*} \\
(0.249)\end{array}$ \\
\hline $\begin{array}{c}\text { Hotel Facilities } \\
\times \text { MR Rate }\end{array}$ & & & $\begin{array}{c}0.052 \\
(0.032)\end{array}$ \\
\hline $\begin{array}{c}\text { Room Facilities } \\
\times \text { MR Rate }\end{array}$ & & & $\begin{array}{l}-0.005 \\
(0.019)\end{array}$ \\
\hline $\begin{array}{c}\text { Accessibility } \\
\times \text { MR Rate }\end{array}$ & & & $\begin{array}{c}0.102^{* * 3} \\
(0.044)\end{array}$ \\
\hline $\begin{array}{c}\text { Price } \\
\times \text { MR Rate }\end{array}$ & & & $\begin{array}{c}0.000^{*} * 4 \\
(0.000)\end{array}$ \\
\hline Adjusted $\mathrm{R}^{2}$ & 0.131 & 0.199 & 0.267 \\
\hline Sig. F Change & 0.001 & 0.002 & 0.016 \\
\hline
\end{tabular}

${ }^{*} p<0.05,{ }^{* *} p<0.01, * 1$ Beta $=-0.233 * 2$ Beta $=0.291$

$※ 3$ Beta $=0.207 \% 4$ Beta $=0.368$

Parentheses indicate Std. error

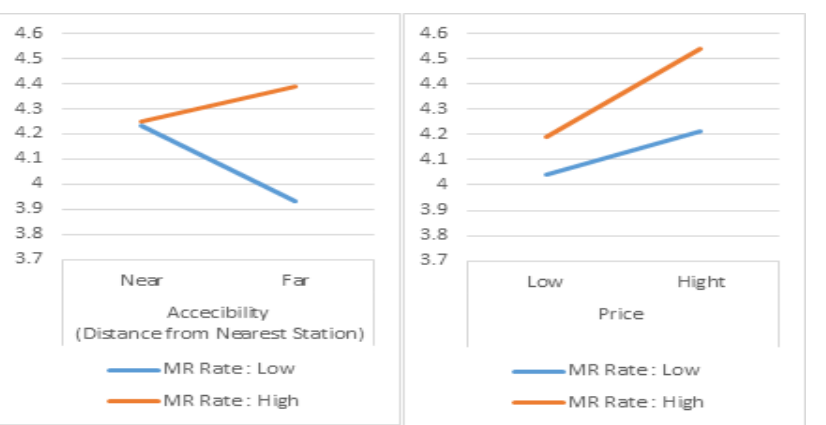

Figure 2: Moderate Effect on Rate 
이처럼, 본 연구의 가설 $\mathrm{H}$ 는 입지도와 가격에 한해서 부분 적으로 지지되었음을 알 수 있다.

\section{5. 연구 결과 토론 및 시사점}

\section{1. 실무적 시사점}

일본인 관광객을 주요 타깃 고객으로 운영되는 라쿠텐 트래 블에 등록된 서울 소재의 120 개 호텔을 대상으로 MR현황을 살펴본 결과, 25 개의 호텔에서 적극적으로 일본어에 의한 $\mathrm{MR}$ 을 실시하고 있는 것으로 나타났다. 이는 TripAdvisor 등의 국 제적인 온라인 플랫폼을 대상으로 이루어진 선행연구의 조사 결과와 비교하여 유사한 수치라 할 수 있으며, 라쿠텐 트래블 이 국내에서는 알려지지 않은 일본 로컬 플랫폼인 점을 고려 하면, 의식적으로 일본인 관광객에 초점을 맞춘 $\mathrm{MR}$ 관리가 적 정하게 실시되고 있는 것으로 판단할 수 있다. 다만 MR속도 에 있어서는 평균 41일이 소요되며, 경우에 따라서는 6 개월 가까운 시간이 지난 후에 $\mathrm{MR}$ 을 실시하는 호텔도 관찰되는 등, 전체적으로 빈번한 관리가 이루어지지는 않는다는 점도 확인 되었다. 앞선 회귀분석의 결과에서도 알 수 있듯이, MR비율이 평점 향상에 중요한 요소로 작용되고 있으며, 잠재고객이 해당 호텔에 대한 후기 정보를 열람했을 때 조금이라도 더 높은 $\mathrm{MR}$ 비율을 노출시키기 위해서는, MR속도를 높이는 것이 평점 을 개선하기 위한 적절한 해결책이 될 수 있다. 따라서 각 호 텔은 향후 MR관리에 있어서, 그 빈도를 높이는 것을 검토할 필요가 있다고 생각된다.

또한 MR비율의 조절효과를 확인하기 위한 가설검정 결과, 총 6 개의 호텔 속성 변수 중, 접근성과 가격에 한해서 평점에 유의한 영향을 끼치며, MR비율이 그 영향을 유의하게 조절하 는 것이 확인되었다. 본 연구결과를 통해, 입지적인 문제로 인 해 고객만족도 관리에 고민을 하고 있던 호텔관리자에 중요한 시사점을 제공할 수 있다고 생각된다. 입지조건은 사회의 인프 라가 확충되지 않는 이상 단기적으로 쉽게 극복할 수 있는 제 약이 아니기 때문에, 접근성과 관련하여 고객 만족을 개선하는 것에는 큰 어려움이 따른다. 하지만, MR관리를 철저히 하여 그 비율을 높임으로써, 이러한 접근성의 제약을 효과적으로 극 복 및 해결할 수 있는 것으로 나타났다. 또한 고차원의 서비스 제공을 위한 서비스 원가 상승으로 높은 가격을 책정한 호텔 인 경우, $\mathrm{MR}$ 비율을 높임으로써 평점의 상승을 보다 효과적으 로 달성할 수 있다는 사실도 확인되었다.

마지막으로, MR비율은 Xie et al.(2016) 등에서도 확인된 바 와 같이, 조절효과뿐만 아니라 평점에 직접적인 영향을 미치는 사실도 확인되었다. 이렇듯 $\mathrm{MR}$ 비율의 상승은 다각적으로 평 점상승에 기여할 수 있다. 종합적으로 이러한 결과를 통해 일 본인 관광객의 만족도 향상 및 평판관리를 위해서는 고객 후 기에 대한 $\mathrm{MR}$ 비율을 늘리는 것이 중요하다는 경영학적 함의 를 본 연구를 통해 확인할 수 있었다.

\section{2. 학문적 시사점}

본 연구의 이론적 공헌은 기존선행연구에서와 같이 $\mathrm{MR}$ 비율 을 독립변수로 설정하여 직접적인 영향력을 확인하기보다는, $\mathrm{MR}$ 비율을 조절변수로 설정함으로써, 호텔의 속성이 평점에
미치는 영향이 $\mathrm{MR}$ 비율에 따라 어떻게 변화하는지에 초점을 맞추었다는 점이다. 이에 따라 MR관리수준이 평점에 미치는 유의한 효과를 다각적으로 검토할 수 있었다. MR을 조절변수 로 설정한 소수의 선행연구에서는, 평점이 아닌 재무성과를 주 로 종속변수로 설정하고 있었는데, 잠재고객에 미치는 영향을 고려하면, 평점을 종속변수로 설정하는 본 연구의 설계가 보다 유의미한 시사점을 제공할 수 있다고 생각된다. 또한 국내에서 는 지금까지 고객 후기의 영향력에 초점을 맞춘 연구가 중점 적으로 진행되어 왔으며, MR의 영향력에 대한 연구는 시행되 지 않았었으나, 본 연구를 통해 MR관리수준의 현황과 그 영 향력을 확인함으로써, 후행연구를 위한 기반을 제공할 수 있었 다. 고객 후기가 공유되는 온라인 플랫폼은 각자 제공하는 정 보의 종류가 상이하여, 연구 대상으로 어떠한 플랫폼을 활용할 지에 따라 변수를 다종다양하게 설정할 수 있다. 이러한 온라 인 플랫폼의 특성을 십분 활용하여, 추후에도 $\mathrm{MR}$ 의 유효성에 대한 정량적 연구가 다각적으로 이루어질 수 있기를 기대해본 다.

\section{3. 연구의 한계점 및 향후 연구방향}

본 연구는 해외의 로컬 플랫폼에서 국내 호텔에 대한 데이 터를 수집해야 한다는 연구 설계상의 한계로 인해, 충분한 데 이터 확보에 어려움이 있었으며, 이에 따라 2016년도부터 2018년도까지의 3년간의 데이터를 전부 통합한 평균치를 구해 서 분석에 활용할 수밖에 없었다. 데이터가 충분히 확보되었더 라면, 평균치를 1 년이나 1 개월 등 보다 작은 단위로 나누어서 계산한 후, 독립변수와 종속변수의 시간적인 전후관계도 고려 한 분석을 실시 할 수도 있었을 것이다. 이 한계를 개선하기 위해서는 TripAdvisor나 Expedia와 같이 더욱 다량의 데이터가 축적되어있는 플랫폼을 활용하는 등 연구 설계 자체를 달리해 야 할 필요가 있다고 생각된다. 또한 평점에 영향을 미치는 호 텔의 속성으로서, 본 연구에서 언급된 6 가지의 외형적인 특성 외에도, 직원의 친절도, 객실의 청결도, 호텔의 분위기 등 수 치로 나타내기 힘든 요소도 중요하게 다루어져야 할 필요가 있으나, 객관적인 데이터를 바탕으로 진행된 연구의 특성상 이 러한 요소들을 고려할 수 없었다. 그리고 본 연구는 정량적인 수치데이터에 입각한 분석이기 때문에, 실제로 MR의 내용이 어떠했는지는 고려 대상에서 제외하고 있다. 하지만 $\mathrm{MR}$ 을 얼 마나 실시했는지도 중요한만큼, $\mathrm{MR}$ 을 어떻게 실시했는지도 중요하게 논의되어야할 사안이다. 이러한 한계를 보완하기 위 하여, 추후에 내용분석이나, 실험을 통한 연구 등이 후속되어 야 할 필요가 있다. 마지막으로, 호텔의 등급에 따라서서 조절 효과가 상이할 수 있으나, 부족한 표본으로 인하여 실시할 수 없었다. 따라서 서울 뿐 아니라 부산이나 제주 등의 지역을 포 함한 표본 수집을 통해, 추후 호텔의 등급별 조절효과의 차이 를 고찰할 필요도 있다고 생각된다.

\section{References}

Black, H. G., \& Kelley, S. W. (2009). A storytelling perspective on online customer reviews reporting service failure and recovery. Journal of Travel \& Tourism Marketing, 26(2), 169-179. 
Chevalier, J. A., Dover, Y., \& Mayzlin, D. (2018). Channels of Impact: User reviews when quality is dynamic and managers respond. Marketing Science, 37(5), 688-709.

Gu, B., \& Ye, Q. (2014). First step in social media: Measuring the influence of online management responses on customer satisfaction. Production and Operations Management, 23(4), 570-582.

Grönroos, C. (1990). Service management and marketing: Managing the moments of truth in service competition. San Francisco, CA: Jossey-Bass.

Jang, J. (2016). A New Framework for Service Quality Cost Management. The Journal of Cost Accounting Research, 40(1), 122-132.

Lee, J. W. (2012). The impact of foreign exchange rates on international travel: the case of South Korea. Journal of Distribution Science, 10(9), 5-11.

Lee, J. W., \& Kwag, M. (2017). Corporate marketing strategy using social media: a case study of the Ritz-Carlton Seoul. Journal of Asian Finance, Economics and Business, 4(1), 79-86.

Li, C., Cui, G., \& Peng, L. (2017). The signaling effect of management response in engaging customers: A study of the hotel industry. Tourism Management, 62, 42-53.

Lui, T. W., Bartosiak, M., Piccoli, G., \& Sadhya, V. (2018). Online review response strategy and its effects on competitive performance. Tourism Management, 67, 180-190.

McCarthy, L., Stock, D., \& Verma, R. (2010). How travelers use online and social media channels to make hotel-choice decisions.

Min, H., Lim, Y., \& Magnini, V. P. (2015). Factors affecting customer satisfaction in responses to negative online hotel reviews: The impact of empathy, paraphrasing, and speed. Cornell Hospitality Quarterly, 56(2), 223-231.

Parasuraman, A., Zeithaml, V. A., \& Berry, L. L. (1985). A conceptual model of service quality and its implications for future research. Journal of marketing, 49(4), 41-50.

Park, J. H., \& Chung, L. C. (2016). The impact of reputation of culture \& tourism oriented markets on revisit and WOM intention in traditional markets. Journal of Distribution Science, 14(8), 77-86.

Park, S. Y., \& Allen, J. P. (2013). Responding to online reviews: Problem solving and engagement in hotels. Cornell Hospitality Quarterly, 54(1), 64-73.

Proserpio, D., \& Zervas, G. (2017). Online reputation management: Estimating the impact of management responses on consumer reviews. Marketing Science, 36(5), 645-665.

Rose, M., \& Blodgett, J. G. (2016). Should hotels respond to negative online reviews?. Cornell Hospitality Quarterly, 57(4), 396-410.

Shaw-Ching Liu, B., Sudharshan, D., \& Hamer, L. O. (2000). After-service response in service quality assessment: a real-time updating model approach. Journal of Services Marketing, 14(2), 160-177.

Wei, W., Miao, L., \& Huang, Z. J. (2013). Customer engagement behaviors and hotel responses. International Journal of Hospitality Management, 33, 316-330.

Xie, K. L., Zhang, Z., \& Zhang, Z. (2014). The business value of online consumer reviews and management response to hotel performance. International Journal of Hospitality Management, 43, 1-12.

Xie, K. L., Zhang, Z., Zhang, Z., Singh, A., \& Lee, S. K. (2016). Effects of managerial response on consumer eWOM and hotel performance: Evidence from TripAdvisor. International Journal of Contemporary Hospitality Management, 28(9), 2013-2034.

Xie, K., Kwok, L., \& Wang, W. (2017). Monetizing managerial responses on TripAdvisor: Performance implications across hotel classes. Cornell Hospitality Quarterly, 58(3), 240-252. 